\title{
Hybrids of Iron-Filled Multiwall Carbon Nanotubes and Anticancer Agents as Potential Magnetic Drug Delivery Systems: In Vitro Studies against Human Melanoma, Colon Carcinoma, and Colon Adenocarcinoma
}

\author{
Sławomir Boncel, ${ }^{1}$ Anna Pluta, ${ }^{1}$ Magdalena Skonieczna, ${ }^{2}$ Andrzej Gondela, ${ }^{1}$ \\ Barbara Maciejewska, ${ }^{3}$ Artur P. Herman,, Rafał G. Jędrysiak, ${ }^{1}$ Sebastian Budniok, ${ }^{1}$ \\ Kamila Komędera, ${ }^{4}$ Artur Błachowski, ${ }^{4}$ and Krzysztof Z. Walczak ${ }^{1}$ \\ ${ }^{1}$ Department of Organic Chemistry, Bioorganic Chemistry and Biotechnology, Silesian University of Technology, \\ Krzywoustego 4, 44-100 Gliwice, Poland \\ ${ }^{2}$ Biosystems Group Department of Automatics, Electronics and Informatics, Institute of Automatic Control, \\ Silesian University of Technology, Akademicka 16, Gliwice, Poland \\ ${ }^{3}$ NanoBioMedical Centre, Adam Mickiewicz University in Poznań, Umultowska 85, 61-614 Poznań, Poland \\ ${ }^{4}$ Mössbauer Spectroscopy Laboratory, Institute of Physics, Pedagogical University, Podchorążych 2, 30-084 Kraków, Poland
}

Correspondence should be addressed to Sławomir Boncel; slawomir.boncel@polsl.pl

Received 17 January 2017; Revised 9 April 2017; Accepted 15 June 2017; Published 31 July 2017

Academic Editor: Raul Arenal

Copyright (C) 2017 Sławomir Boncel et al. This is an open access article distributed under the Creative Commons Attribution License, which permits unrestricted use, distribution, and reproduction in any medium, provided the original work is properly cited.

Cell type, morphology, and functioning are key variables in the construction of efficient "drug-vehicle" hybrids in magnetic drug delivery. Iron-encapsulated multiwall carbon nanotubes (Fe@MWCNTs) appear as promising candidates for theranostics due to in situ chemical catalytic vapor deposition (c-CVD) synthesis, straightforward organic functionalization, and nanoneedle (1D) behavior. Here, model hybrids were synthesized by exploring C-sp $p^{2}$ chemistry $((1+2)$-cycloaddition of nitrenes and amidation) of the outer MWCNT walls combined with anticancer agents, that is, 5-fluorouracil (5FU), purpurin (Purp), and 1,8-naphthalimide DNA intercalators (NIDIs), via linkers. Analyses of the Fe@MWCNT vehicles by SEM, TEM, and Raman spectroscopy revealed their morphology while Mössbauer spectroscopy confirmed the presence of encapsulated ferromagnetic iron-based nanodomains. Cytotoxicity of the hybrids was studied using a $24 \mathrm{~h}$ MTS assay combined with the apoptosis and life cycle assays against human melanoma (Me45), colon carcinoma (HCT116+), and colon adenocarcinoma (Caco-2). The cells had different sensitivity to the vehicles themselves as well as to the hybrids. MWCNT-based covalent hybrids of 5FU and Purp emerged as the most promising systems against Me45 and HCT116+ cell lines with the highest in vitro cytotoxicity and proapoptotic activity. Furthermore, nanotubes bearing 4-nitro- and 4-( $N$-morpholinyl)-1,8-naphthalimide DNA intercalators appear as a promising candidate for the treatment of Caco-2.

\section{Introduction}

With the constantly growing number of new cases worldwide, cancer diseases continue to require more selective and more efficient therapies $[1,2]$. Among a variety of types, colorectal cancer is the third most frequent cancer accounting for $10 \%$ of all cases worldwide while melanomas develop with the highest rate of new incidents [3]. A recent rise of nanotechnology has poured new hopes to conquering cancer and the research with the "nano" descriptor yielded numerous successful implementations of nanomedicine to medical practice [4]. Nanomedicine exploits therapeutic and/or diagnostic (or combined "theranostic") agents as the key field of commercialization of anticancer products [5]. And here, locoregional therapy using magnetic drug delivery systems (DDSs) emerges as one of the most promising approaches to cure 
cancer [6]. DDSs are composed of therapeutic agents attached to the surface of magnetic nanoparticles or encapsulated within a nanocomposite mixture of a polymer and magnetic nanoparticle. Ideal properties for DDSs cover full biocompatibility, high magnetization, and minimal magnetic remanence at the removal of magnetic field (reducing aggregation and enabling fast excretion). This approach with numerous in vivo studies exploits, for example, various polymer-drug conjugates based, for example, on polyethylene glycol (PEG), $N$-(2-hydroxypropyl)methacrylamide (HPMA), polymeric micelles, and nanoparticle carriers which can be designed with respect to absorption, distribution, metabolism, and excretion (ADME scheme) of numerous anticancer drugs. And so, in one of the more distinguished examples, a doxorubicin- $\mathrm{Fe}_{3} \mathrm{O}_{4}$ complex was prepared by coordination chemistry in which an "interconnecting" $\mathrm{Fe}^{2+}$ cation served as a bridge between phenolic - $\mathrm{OH}$ groups of the drug molecule and superparamagnetic surface of $\mathrm{Fe}_{3} \mathrm{O}_{4}$, and the hybrid was covered by $\mathrm{PEGylated} \mathrm{surface-OH}$ group [7]. In another variant, silica-coated $\mathrm{Fe}_{3} \mathrm{O}_{4}$ nanospheres were coated with redox-responsive cyclodextrin molecules and, after their uptake by cells, high intracellular glutathione concentration caused the pores to become unblocked, liberating the drug [8]. In another example of magnetically targeted therapy, Liu and coworkers have developed $\mathrm{Fe}_{3} \mathrm{O}_{4}$ nanoparticles encapsulated within a poly[aniline-co- $\mathrm{N}$-(1-one-butyric acid)] outer shell and epirubicin was immobilized on the polymer coating. The hybrid was then targeted to the brain using focused ultrasound and magnetic targeting as a synergistic delivery system [9].

Colon carcinomas [10] and melanomas [11] are composed of cells of various morphologies and frequently undergo dangerous metastasis [12]. While response to chemotherapeutics can strongly vary, rapid growth of the cells typically corresponds to drug sensitivity [13]. Hence, on the one hand, when designing targeted therapy systems, both chemical structure of a drug and parameters of its loadable vehicle (frequently forming a multifunctional hybrid) must be addressed. On the other hand, morphology, functioning, and proliferation rate of the cells are a highly changeable drug target. Such a set of variables requires enhanced uptake of "drug-vehicle" hybrids as quickly maneuverable "Trojan horses," by definition fully loaded with cleavable chemotherapeutic agents and safely excretable after unloading.

In the midst of many magnetic nanoparticles applicable in medicine, iron-encapsulated multiwall carbon nanotubes (Fe@MWCNTs) emerge as powerful drug vehicles mainly due to convenient functionalization and needle-like permeation of cells [14]. Nevertheless, continuously disputable concerns in pulmonary toxicity of long, nonfunctionalized, and nonindividualized MWCNTs [15] led to delays in clinical trials of systems based on nanotubes. On the other hand, today, there is no doubt that short, functionalized with polar moieties, and individualized MWCNTs offer a hope to be tested clinically [16]. But earlier in vitro [17] and in vivo [18] reports confirmed that, after functionalization, even $>40 \mu \mathrm{m}$ long Fe@MWCNTs, providing individualized (i.e., not aggregated) nanotubes, could be considered as enzymatically degradable $[19,20]$ and hence excretable drug vehicles [21].
Although significant progress in the field of "nanotube against cancer" has been already made and extensive research continues, some of the key challenges remain [22]. And, apart from mechanisms of in vivo cytotoxicity, biodistribution, effective targeting issues, and routes of the MWCNT excretion, the most critical of them is to (1) design new routes of mild and efficient "drug-to-nanotube" tethering, (2) identify selective anticancer "drug-nanotube" hybrids towards specific cells, and (3) reveal their potential in short period therapies [23].

Pure MWCNTs are diamagnetic [24] and their magnetic steerability must be achieved by combining with ferro- or superparamagnetic components [25-27], for example, by decoration with $\mathrm{Fe}_{3} \mathrm{O}_{4}$ [28] or Fe encapsulation (at the stage of c-CVD synthesis or via capillary forces as a posttreatment) [29]. Indeed, as c-CVD is a convenient and tunable one-step synthesis of Fe@MWCNTs, we decided to focus on effective loading of Fe@MWCNTs with chemotherapeutics representing various mechanisms of cytotoxicity and to anchor the drugs using different chemical routes. In "nonmagnetic" but otherwise targeted delivery, MWCNTs have served as vehicles for strong cytostatic drugs, for example, cisplatin [30, 31]. E.g. Bhirde et al. have shown that MWCNTs-EGF-cisplatin quickly reached the squamous carcinoma cells and significantly reduced their proliferation [32]. However, as cisplatin selectively attacks squamous cells, much more attention was devoted to anthracycline drugs, particularly doxorubicin (Dox) which exhibits a broader spectrum of activity [33, 34]. Purpurin (Purp) displays a similar activity to Dox [35]. It is an active compound in photodynamic therapy [36] and demonstrates an ability to inhibit topoisomerase II as well as intercalate DNA [37]. In addition, its latent hydroquinone moiety may be metabolized generating a large number of free radicals damaging both DNA and cell membrane. Hence, Purp is currently considered as the important alternative of Dox. 5-Fluorouracil (5FU) is a well-established anticancer drug exerting cytotoxicity by affecting DNA synthesis and inhibiting cell proliferation [38]. In turn, 1,8-naphthalimides are fluorescent DNA intercalators binding preferentially to the A-D base pairs [39-41].

In this work, extending our recent studies on in vitro magnetic targeting of breast cancer cells (T47D) with purpurinand 5FU-based Fe@MWCNT hybrids [42], we present anticancer activity and influence to selected cancer cells' life cycle of various covalent and noncovalent "drug-nanotube" hybrids based on Purp, 5FU, and 1,8-naphthalimide DNA intercalators (NIDIs).

\section{Results and Discussion}

2.1. Synthesis and Physicochemical Properties of Nanotube Vehicles. Fe@MWCNTs were synthesized via a known cCVD protocol using the highest possible concentration (9.6 wt.\%) of ferrocene in toluene as a feedstock [43] and were optionally oxidized with a nitrating mixture [17]. Morphology of the magnetically steerable nanotube vehicles was studied using SEM, TEM, and Raman spectroscopy (Figure 1). SEM image showed that Fe@MWCNT grew as vertically aligned nanotube films (also called "carpets" or 


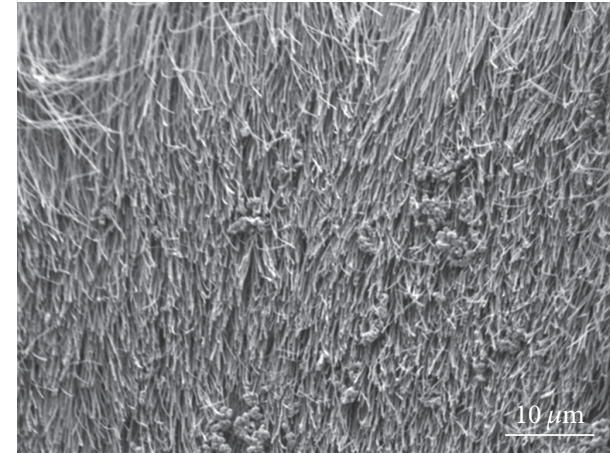

(a)

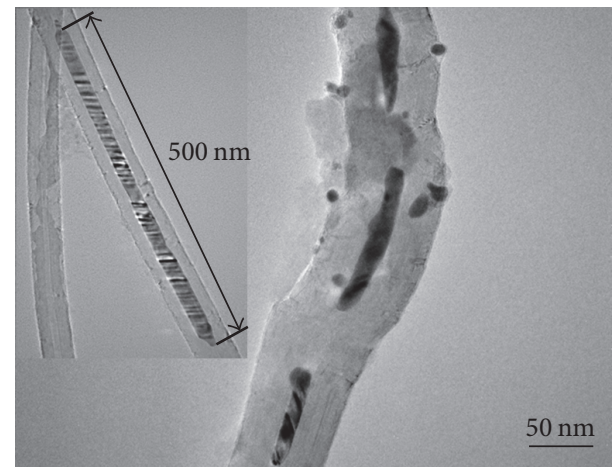

(b)

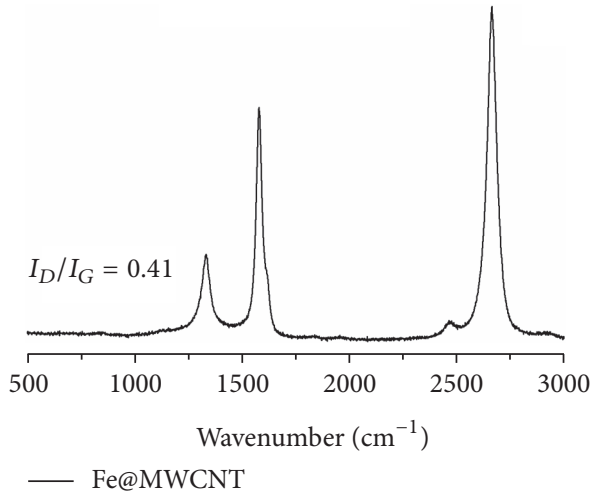

(c)

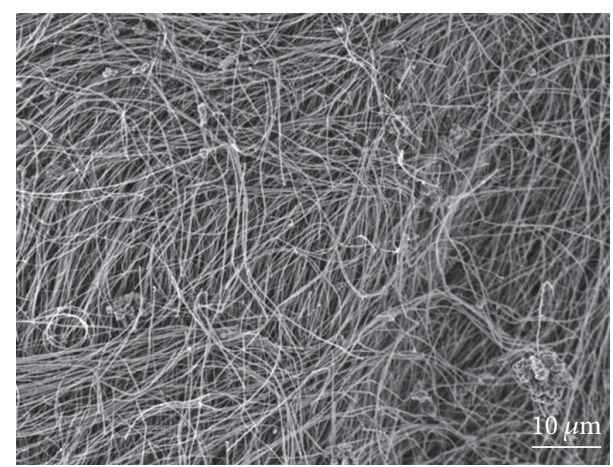

(d)

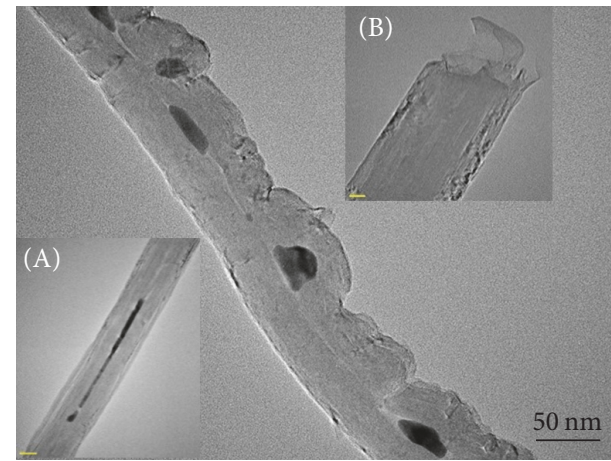

(e)

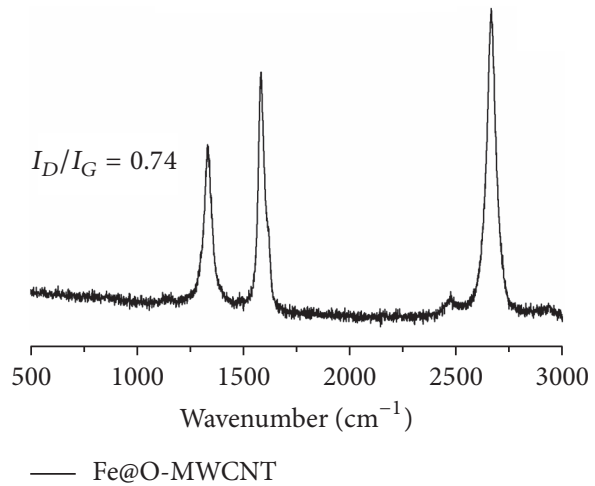

(f)

Figure 1: SEM and TEM images of Fe@MWCNTs (a, b) and Fe@O-MWCNTs (d, e); Raman spectra of MWCNTs (c) and O-MWCNTs (f); inset in (b) shows ca. $500 \mathrm{~nm}$ long nanotube core filled with magnetic iron-based phases; insets in (e) show (A) still present nanotube Fe core and (B) removed Fe-based "cork" after oxidative treatment, that is, an open nanotube tip.

"forests") (Figure 1(a)). The as-grown nanotube bundles display a significant free volume (in terms of the presence of interstices between the outer nanotube shells) reaching up to 90 vol.\% and are practically indispersible in any solvent [44]. Individual Fe@MWCNTs were nonuniformly filled with iron nanoparticles visible in TEM image as from partially to continuously filled nanotube channels (Figure 1(b)). An inset in Figure 1(b) shows an extra-long, $0.5 \mu \mathrm{m}$ long filling inside the nanotube channel. In a few cases, some onion-like graphitic excrescences containing iron nanospheres (removable under oxidation) could be found on the nanotubes' outermost layers. The outer and inner Fe@MWCNT diameters (ODs and IDs) were nonuniform and varied not only between different but also for particular nanotubes; ODs and IDs were found to be equal to $44 \pm 25$ and $12 \pm 6 \mathrm{~nm}$, respectively. The length of pristine nanotubes was $100 \pm 20 \mu \mathrm{m}$, while oxidation led to their partial cutting and the length was reduced to $50 \pm 30 \mu \mathrm{m}$ yielding nanotubes which fall into a biocompatible and water-dispersible category [19-21]. Raman spectrum of Fe@MWCNT (Figure 1(c)) shows three dominating signals at 1332,1579 , and $2662 \mathrm{~cm}^{-1}$ which can be assigned to $D$ (disorder), G- (tangential graphite), and $G^{\prime}$ - (second-order 
TABle 1: ${ }^{57} \mathrm{Fe}$ Mössbauer spectroscopy parameters for Fe@MWCNTs and Fe@O-MWCNTs at room temperature [47, 48].

\begin{tabular}{lccccc}
\hline Sample/phase & $C(\%)$ & $S(\mathrm{~mm} / \mathrm{s})$ & $\Delta(\mathrm{mm} / \mathrm{s})$ & $B(\mathrm{~T})$ & $\Gamma(\mathrm{mm} / \mathrm{s})$ \\
\hline Fe@MWCNTs & & & & & \\
$\gamma$-Fe & 40 & -0.10 & - & - & 0.18 \\
$\alpha$-Fe & 34 & 0.01 & - & 33.0 & 0.18 \\
$\mathrm{Fe}_{3} \mathrm{C}$ & 26 & 0.20 & 0.03 & 20.6 & 0.28 \\
$\mathrm{Fe@O-MWCNTs}$ & & & & & \\
$\gamma$-Fe & 42 & -0.09 & - & - & 0.17 \\
$\alpha$-Fe & 53 & 0.00 & - & 33.2 & 0.17 \\
$\mathrm{Fe}_{3} \mathrm{C}$ & 5 & 0.14 & 0.18 & 21.0 & 0.27 \\
\hline
\end{tabular}

$C$ (\%): relative contribution of various iron phases to the absorption cross section; it corresponds to iron abundancies as particular phases; $S(\mathrm{~mm} / \mathrm{s})$ : spectral shift versus shift of $\alpha$-Fe at room temperature; $\Delta(\mathrm{mm} / \mathrm{s})$ : electric quadrupole splitting; $B(\mathrm{~T})$ : magnetic hyperfine field; $\Gamma(\mathrm{mm} / \mathrm{s})$ : absorber line width. Errors for all values are of the order of unity for the last digit shown.

harmonic) bands, respectively [45]. Moreover, $D^{\prime}$-peak can be visible as a shoulder at $1610 \mathrm{~cm}^{-1}$ once the signal at the maximum of $1579 \mathrm{~cm}^{-1}$ was deconvoluted.

After oxidation of pristine Fe@MWCNTs for 20 min under reflux in a mixture of sulfuric acid $(98 \%)$ and nitric acid $(68 \%)(3 / 1, \mathrm{v} / \mathrm{v})$ (for a detailed experimental protocol, please see Supporting Information (SI) available online at https://doi.org/10.1155/2017/1262309), the nanotubes changed their morphology into more twisted and entangled shape as visible by SEM (Figure 1(d)). This change took place due to extensive corrugation and formation of numerous grooves as revealed by TEM (Figure 1(e)). TEM images revealed that Fe@O-MWCNTs also contained encapsulated iron nanoparticles but, as determined by elemental analysis, the final Fe content dropped from 7.0 for Fe@MWCNTs to $3.0 \mathrm{wt} . \%$ whereas total $\mathrm{O}$ content (mainly as carboxylic groups) increased from 0 to ca. $18 \mathrm{wt} . \%$ [46]. The decrease in the Fe content after oxidative functionalization was observed due to partial erosion of the Fe nanoparticles from the nanotube tips and excrescences and, to a lesser extent, from the walls. Raman spectroscopy confirmed moderately destructive functionalization of graphene walls as the $I_{D} / I_{G}$ ratio increased to 0.74 (Figures 1 (c) and 1(f)).

Magnetic characterization of Fe@MWCNTs and their oxidized counterparts has revealed that their ferromagnetic behavior was a derivative of the multiphase structure of iron nanoparticles encapsulated in the nanotube cores. ${ }^{57} \mathrm{Fe}$ Mössbauer spectra with the superimposed fitted curves are shown in Figure 2 while the essential results are collected in Table 1.

The sample of Fe@MWCNTs was composed of three iron containing phases, that is, $\gamma$ - $\mathrm{Fe}, \alpha$ - $\mathrm{Fe}$, and $\mathrm{Fe}_{3} \mathrm{C}$. The majority of iron (40 at.\%) resided in the $\gamma$-Fe being paramagnetic at room temperature, 34 at.\% of iron made ferromagnetic $\alpha$ $\mathrm{Fe}$, and the remainder (26at.\%) resided in the magnetically ordered iron carbide $\left(\mathrm{Fe}_{3} \mathrm{C}\right)$. Spectra at high velocity range $( \pm 12 \mathrm{~mm} / \mathrm{s})$ were additionally acquired revealing absence of iron oxides. The sample of Fe@O-MWCNTs (of total Fe content equal to 3 wt.\%) similarly contained metallic $\mathrm{Fe}$
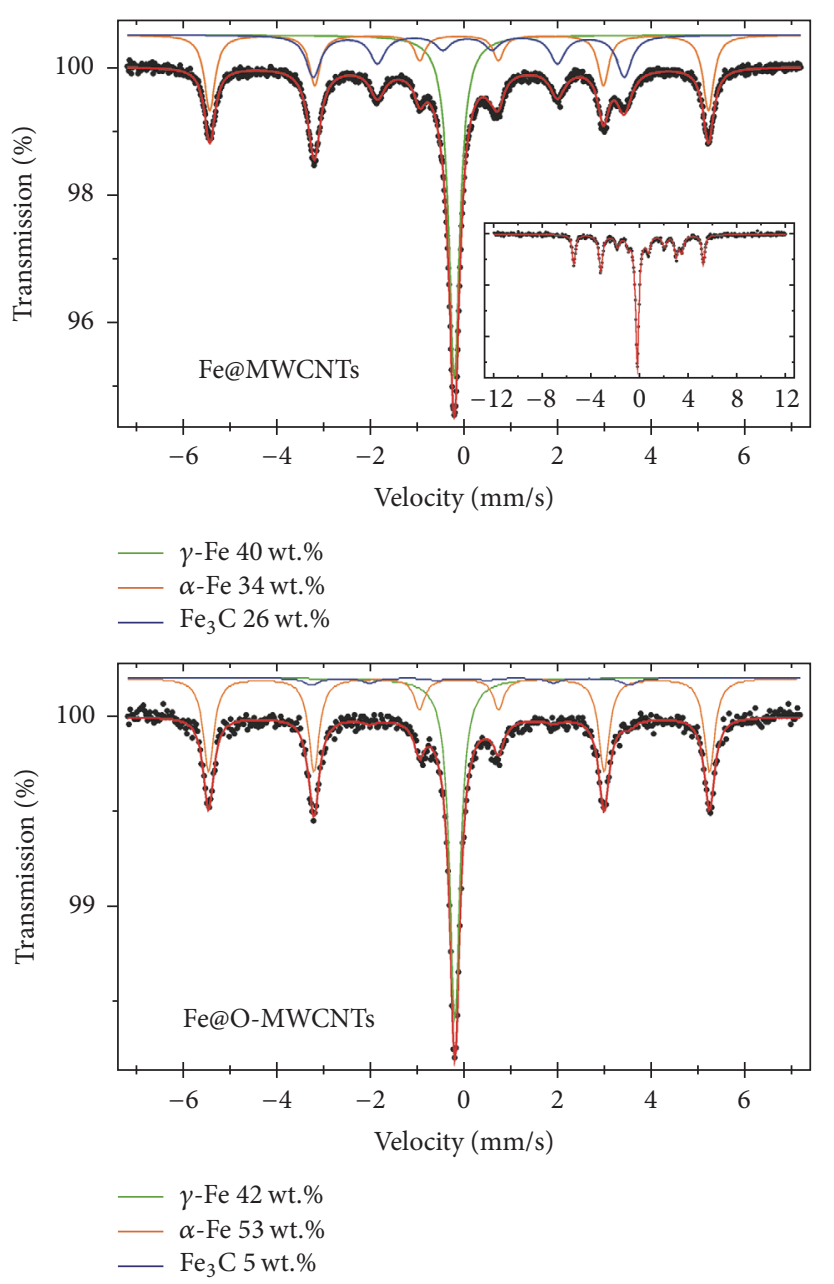

FIgURE 2: ${ }^{57} \mathrm{Fe}$ Mössbauer spectra of Fe@MWCNTs and Fe@OMWCNTs at room temperature.

phases as the dominating components but the content of $\mathrm{Fe}_{3} \mathrm{C}$ (residing typically at the $\mathrm{Fe} / \mathrm{C}$ interphase and hence being the most accessible and susceptible to aggressive oxidizing agents [49]) dropped to as low level as $5 \mathrm{wt} . \%$. Nevertheless, it was clear from magnetic hyperfine field experiments that the concentration of ferromagnetic phases, that is, $\mathrm{Fe}$ and $\mathrm{Fe}_{3} \mathrm{C}$, exhibited maneuverability in the external magnetic field.

2.2. Drugs and "Drug-Nanotube" Hybrids. Purp, 5FU, and NIDIs were used as model anticancer drugs towards immobilization onto Fe@MWCNTs and Fe@O-MWCNTs (Figure 3) (detailed experimental procedures are presented in SI). Purp$\mathrm{N}_{3}$ (2a) was synthesized from Purp via its regioselective $O^{2}$ alkylation with 1-azido-4-bromobutane in the presence of 1,8diazabicyclo[5.4.0] undec-7-ene (DBU) as a deprotonating agent. 5FU, after addition to 2-hydroxyethyl acrylate [50], was equipped with a longer linker in a reaction of the corresponding Michael adduct with 6-azidohexanoic acid, in the presence of 4-(4,6-dimethoxy-1,3,5-triazin-2-yl)-4methylmorpholinium chloride (DMT-MM) as a condensing agent, yielding $5 \mathrm{FU}-\mathrm{N}_{3}$ (2b). Substituted 1,8-naphthalimide 

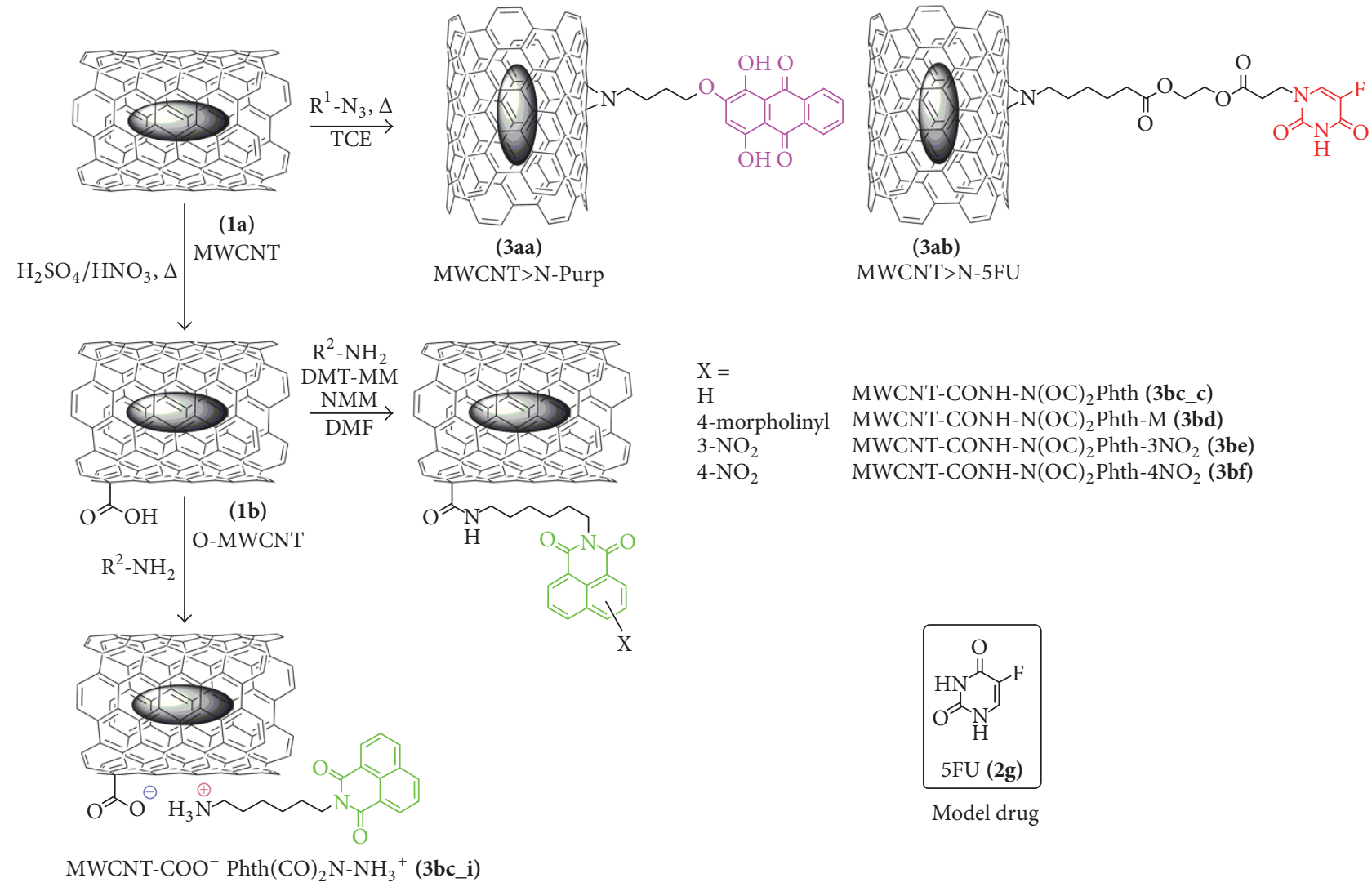

MWCNT $>\mathrm{N}-5 \mathrm{FU}$

FIgURE 3: Synthesis of the "drug-nanotube" hybrids.

derivatives (2c-2f) were synthesized from the appropriate 1,8-naphthalic anhydrides via aminolysis with Boc-protected hexylenediamine (Scheme S1, SI). Purp- $\mathrm{N}_{3}$ (2a) and 5FU$\mathrm{N}_{3}$ (2b) were covalently anchored to MWCNTs using nitrene chemistry yielding MWCNT $>\mathrm{N}$-Purp (3aa) and MWCNT $>\mathrm{N}-5 \mathrm{FU}$ (3ab), respectively (Figure 3).

Pristine Fe@MWCNTs were oxidized to Fe@OMWCNTs (bearing carboxylic groups) according to the protocol depicted earlier (20 min reflux $\mathrm{H}_{2} \mathrm{SO}_{4}$ (98\%) + $\left.\mathrm{HNO}_{3}(68 \%)(3 / 1, \mathrm{v} / \mathrm{v})\right)$ and the latter were subsequently conjugated with variously substituted 1,8-naphthalimide derivatives (2c-2f) using DMT-MM as a condensing agent and giving the appropriate hybrids (3bc_c-bf). Alternatively, $\mathrm{Phth}(\mathrm{CO})_{2} \mathrm{~N}-\mathrm{NH}_{2}$ (2c) treated with O-MWCNTs in DMF formed the "nanotubate" salt (3bcii). The hybrids were obtained with various drug loadings (DLs) (Table 2) as determined by thermogravimetric analysis (TGA) (Figure 4).

DLs were calculated using a range of decomposition determined by projection of the peak onset and offset points (ca. 200 and $800^{\circ} \mathrm{C}$ ) corresponding to minimal and maximal rates of decomposition of the "drug + linker" moieties in the "drug-nanotube" hybrids and further subtraction of the weight loss derived from the linker itself and volatiles (water and organic solvents used for the synthesis and isolation) [5153]. From those values (for the same temperature ranges), weight losses (\%) of MWCNTs and O-MWCNTs were subtracted yielding DLs for the particular "drug-nanotube" hybrids.

Anchoring the chemotherapeutic drugs (or their prodrugs) has left the morphology of the modified nanotubes intact. Nevertheless, this modification changes the surface polarity of nanotubes, their affinity to aqueous media, and hence further binding to cell membranes [54]. In order to visualize uptake and drug unloading from the "drug-nanotube" hybrids, fluorescent and scanning confocal microscopy studies were performed (Figure S1, SI). The observations were possible because all of the hybrids exhibited fluorescence in the spectral range of $4^{\prime}, 6$-diamidino2-phenylindole (DAPI). It was found that "drug-nanotube" hybrids landed, pierced, or in a few cases penetrated cancer cells, similar to our previous studies [42], and the fluorescent drugs were unloaded intracellularly, mainly by diffusion after enzymatic cleavage or physical unloading. The enhanced cell penetration by nanotubes, also in the presence of magnetic field and noncytotoxic to human monocyte macrophage cells, was described by Boncel et al. [42] and Mahmood et al. [55]. The latter complex mechanism opens an additional route of intracellular release in the presence of a magnetic field. It was indeed confirmed that nanotubes, apart from altering cellular metabolic activity, may physically impair the membrane integrity yielding synergetic cytotoxicity [17]. The combination of the above facts with digestibility of MWCNTs 
TABLE 2: Drug loadings (DLs) in the "drug-nanotube" hybrids.

\begin{tabular}{|c|c|c|c|c|}
\hline $\begin{array}{l}\text { Nanotube } \\
\mathbf{1}\end{array}$ & $\begin{array}{c}\text { Drugs (and prodrugs) } \\
\mathbf{2} \\
\end{array}$ & $\begin{array}{c}\text { "Drug-nanotube" hybrid } \\
\mathbf{3} \\
\end{array}$ & $\begin{array}{c}\text { Drug + linker } \\
\text { loading (wt.\%) }\end{array}$ & $\mathrm{DL}(\mathrm{wt} . \%)^{*}$ \\
\hline \multirow{2}{*}{$\begin{array}{l}\text { MWCNT } \\
\text { (1a) }\end{array}$} & Purp- $\mathrm{N}_{3}(2 \mathrm{a})$ & MWCNT>N-Purp (3aa) & 15.0 & 11.8 \\
\hline & $5 \mathrm{FU}-\mathrm{N}_{3}(\mathbf{2 b})$ & MWCNT>N-5FU (3ab) & 42.0 & 15.2 \\
\hline \multirow{5}{*}{$\begin{array}{l}\text { O-MWCNT } \\
\text { (1b) }\end{array}$} & \multirow{2}{*}{ Phth $(\mathrm{CO})_{2} \mathrm{~N}-\mathrm{NH}_{2}(2 \mathrm{c})$} & $\begin{array}{c}{\mathrm{MWCNT}-\mathrm{COO}^{-}}^{-} \\
\mathrm{Phth}(\mathrm{CO})_{2} \mathrm{~N}- \\
\mathrm{NH}_{3}{ }^{+}(\mathbf{3 b c} \mathbf{i})\end{array}$ & 6.0 & 3.4 \\
\hline & & $\begin{array}{l}\text { MWCNT-CONH-N- } \\
\text { (OC) })_{2} \text { Phth } \\
\left(3 \mathbf{b c} \_\mathbf{c}\right)\end{array}$ & 11.5 & 7.0 \\
\hline & $\begin{array}{l}\text { M-Phth }(\mathrm{CO})_{2} \mathrm{~N}- \\
\mathrm{NH}_{2}(\mathbf{2 d})\end{array}$ & $\begin{array}{c}\text { MWCNT-CONH-N- } \\
\text { (OC) })_{2} \text { Phth-M } \\
\text { (3bd) }\end{array}$ & 1.0 & 0.7 \\
\hline & $\begin{array}{c}3 \mathrm{NO}_{2}-\mathrm{Phth}(\mathrm{CO})_{2} \mathrm{~N}- \\
\mathrm{NH}_{2}(\mathbf{2 e})\end{array}$ & $\begin{array}{l}\text { MWCNT-CONH-N- } \\
(\mathrm{OC})_{2} \mathrm{Phth}-3 \mathrm{NO}_{2}(3 \mathbf{b e})\end{array}$ & 3.0 & 2.1 \\
\hline & $\begin{array}{c}4 \mathrm{NO}_{2}-\mathrm{Phth}(\mathrm{CO})_{2} \mathrm{~N}- \\
\mathrm{NH}_{2}(\mathbf{2 f})\end{array}$ & $\begin{array}{l}\text { MWCNT-CONH-N- } \\
(\mathrm{OC})_{2} \mathrm{Phth}-4 \mathrm{NO}_{2}(\mathbf{3 b f})\end{array}$ & 7.0 & 4.8 \\
\hline
\end{tabular}

${ }^{*}$ DL was calculated based on pyrolytic (Ar) TGA and it was calculated per pure drug (i.e., excluding linker) based on the structures in Figure 3.

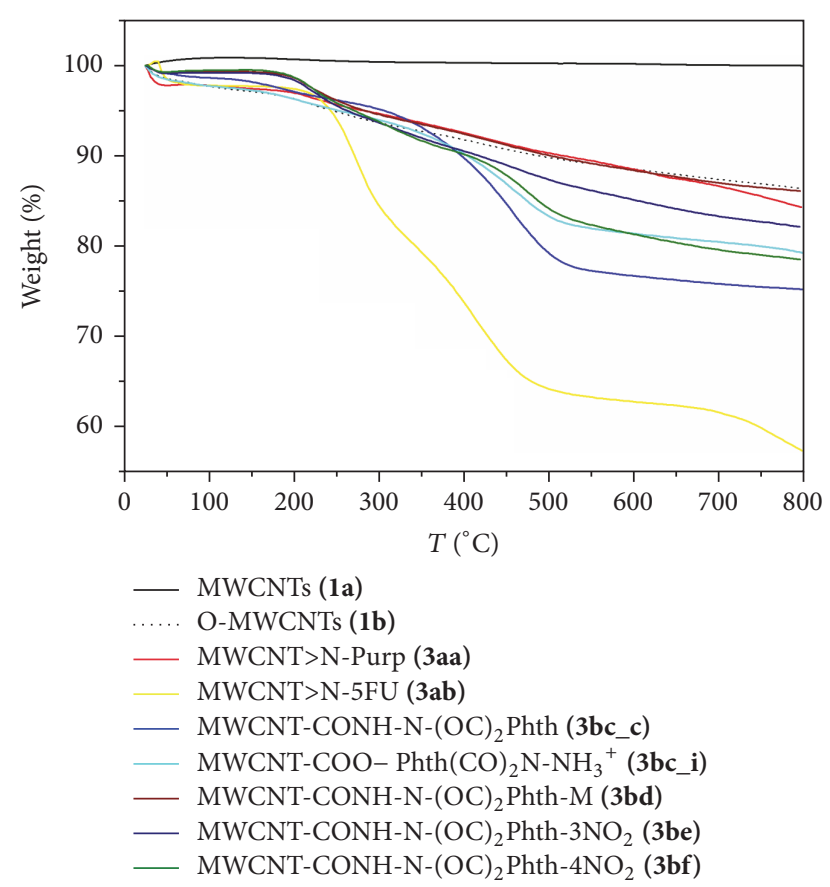

FIGURE 4: TGA curves of nanotube vehicles and "drug-nanotube" hybrids; the analyses were performed under argon at $20^{\circ} \mathrm{C} \mathrm{min}^{-1}$.

by peroxidases [19] establishes perspective premises towards in vivo studies.

2.3. Cytotoxicity of Drugs/“Drug-Nanotube" Hybrids, Induction of Apoptosis, and Influence on the Cancer Cell Cycle. With the aim of evaluating the cytotoxicity of nanotube vehicles, pure anticancer agents (or their prodrugs) as well as "drug-nanotube" hybrids, in the background of pure 5FU as a control drug, were analyzed using a 3-(4,5-dimethylthiazol2-yl)-5-(3-carboxymethoxyphenyl)-2-(4-sulfophenyl)-2Htetrazolium (MTS) assay (Figure 5).

Both types of nanotube vehicles emerged as practically noncytotoxic against Me45 up to $50 \mu \mathrm{g} \mathrm{mL}^{-1}$, whereas pristine MWCNTs (1a) were more cytotoxic for HCT116+ cells than O-MWCNTs (1b). For this cell line, inversely proportional concentration-viability dependence was observed. Moreover, HCT116+ cells were the most sensitive to nanotubes among all of the tested lines. Response of the Caco-2 line to the nanotubes falls in between the responses of Me45 and $\mathrm{HCT}+116$. Me45 cells exhibited high in vitro resistance to "drug-nanotube" hybrids, similar to the nanotube vehicles. Only MWCNT $>$ N-5FU hybrid (3ab) emerged as highly active against Me45 cells killing ca. half of their population at $50 \mu \mathrm{g} \mathrm{mL} \mathrm{mL}^{-1}$. Similar cytotoxicity was achieved by $5 \mathrm{FU}$ at 2000 times lower concentration. MWCNT>N-Purp (3aa) was the most cytotoxic against HCT116+ with ca. $60 \%$ of viable cells at the highest tested concentration. Caco- 2 cells exposed to the "drug-nanotube" hybrids appeared to be the most suitable target for 1,8-naphthalimide-based intercalators anchored to nanotubes, with the 4-nitro derivative ( $3 \mathbf{b f}$ ) as the most active one. Viability of the Caco- 2 cell line at $50 \mu \mathrm{g}$ $\mathrm{mL}^{-1}$ of the MWCNT-CONH-N-(OC) ${ }_{2}$ Phth- $4 \mathrm{NO}_{2}$ hybrid (3bf) was below 35\%. It must be emphasized that this effect was not achievable even at as high concentration of pure drug (2c) as $100 \mu \mathrm{g} \mathrm{mL}^{-1}$. It seems that MWCNTs could exhibit intrinsic cytotoxicity by cellular membrane damage and, for example, interfere with the microtubule dynamics [56-58].

Furthermore, cytotoxicity studies of some of the tested drugs displayed a bimodal activity, particularly $2 \mathbf{a}, \mathbf{2 c}$, and 5FU (2g) against HCT116+ (Figure 5), which in general means higher toxicity at lower dose ranges and lower toxicity at higher doses. Such results are rather commonly known for pharmaceutical tests of different chemical compounds well known from the literature. For example, physiological 

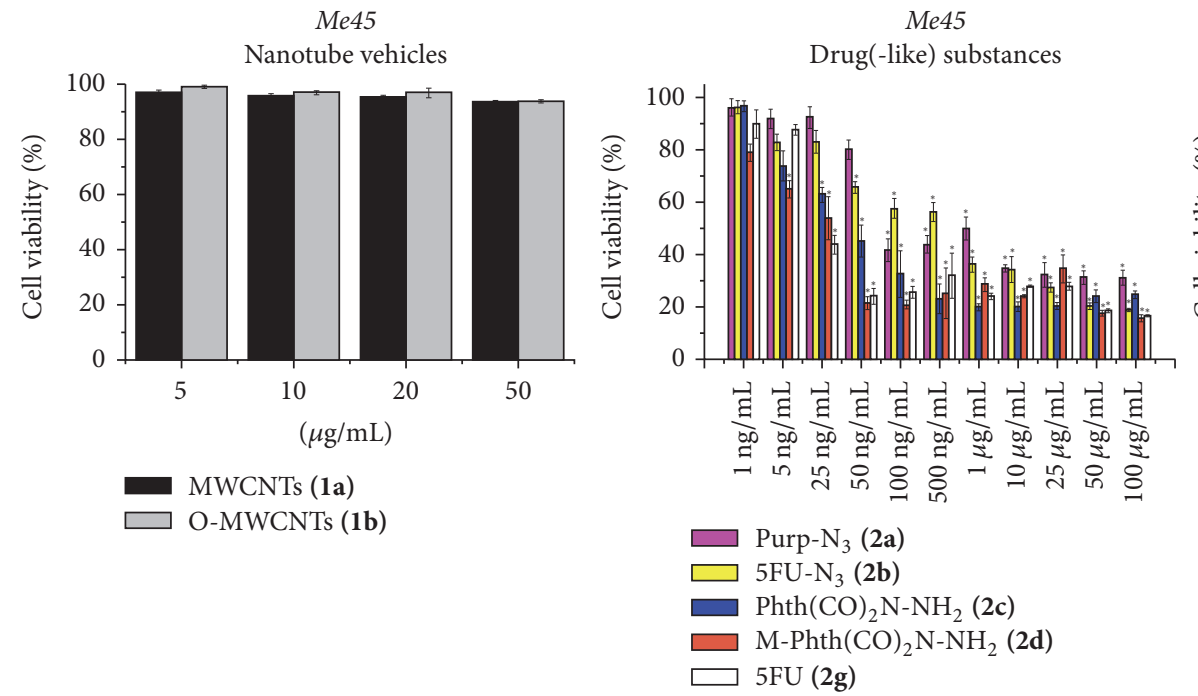

HCT116+

Nanotube vehicles

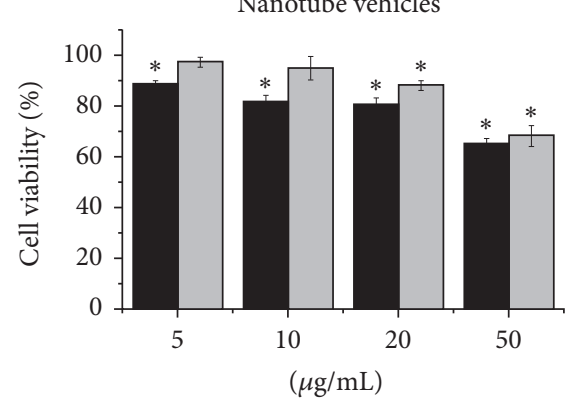

mWCNTs (1a)

$\square$ O-MWCNTs (1b)

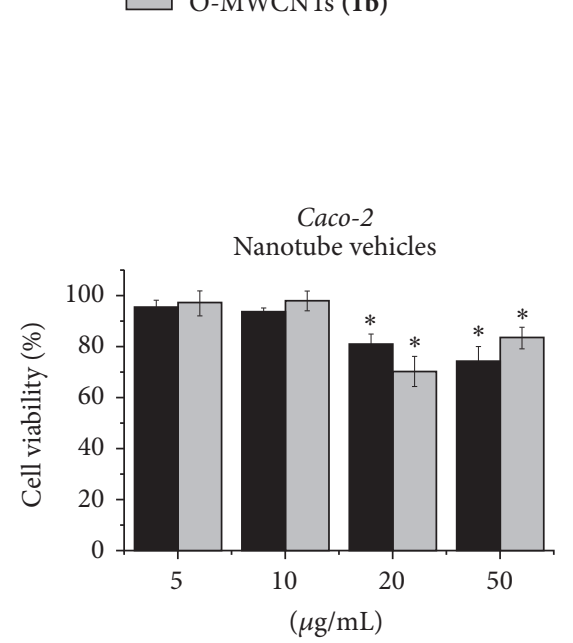

MWCNTs (1a)

O-MWCNTs (1b)
HCT116+

Drug(-like) substances
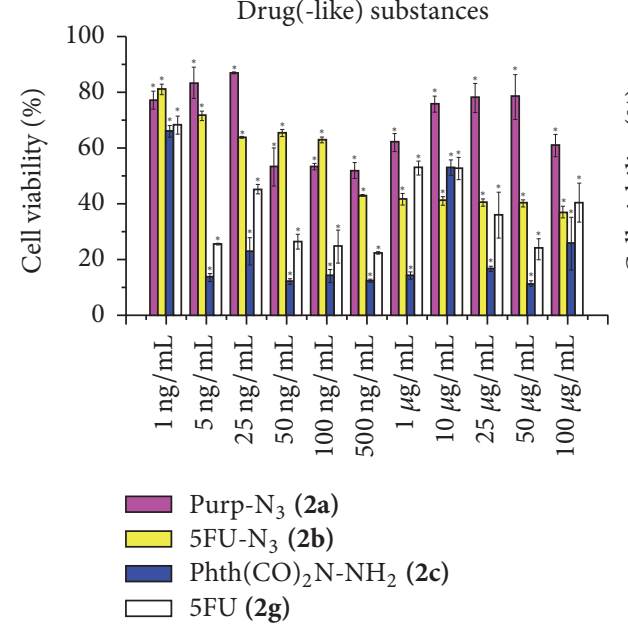

Caco-2 Drug(-like) substances

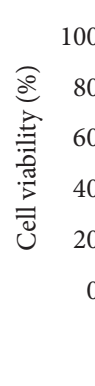




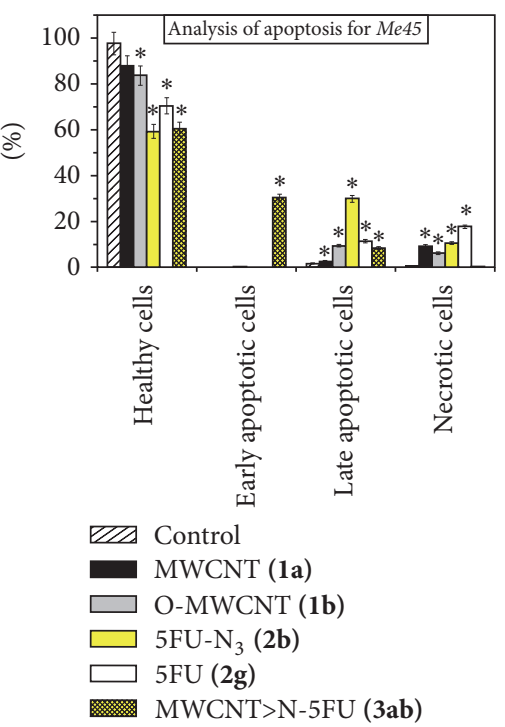

(a)

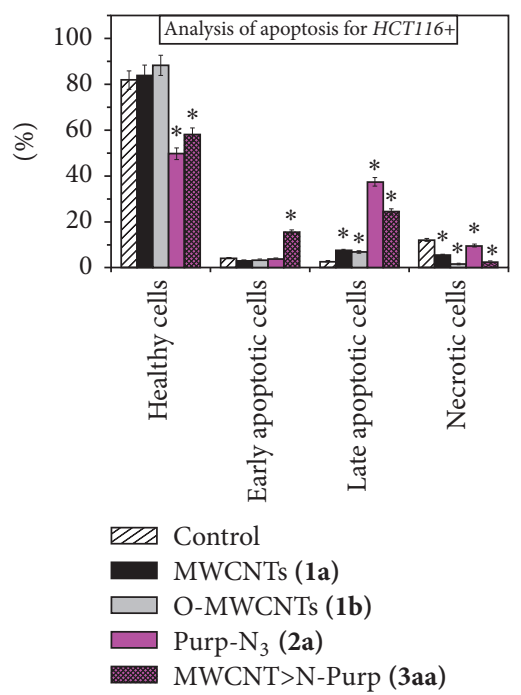

(b)

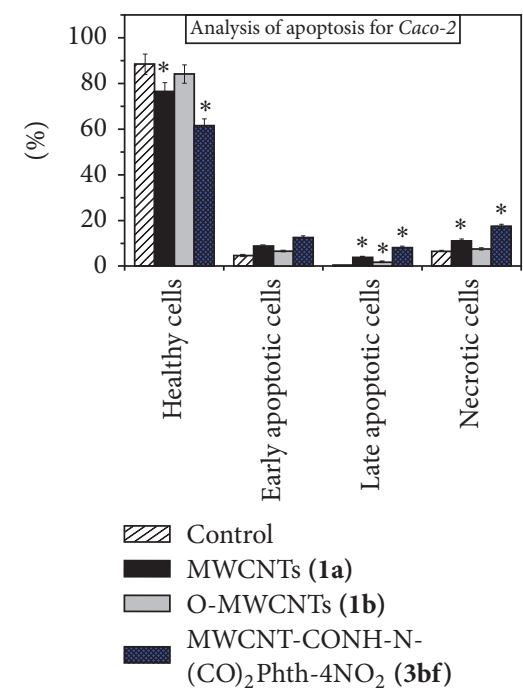

(c)

Figure 6: Analysis of apoptosis in cell lines incubated with Fe@MWCNT/Fe@O-MWCNT vehicles, anticancer agents, and “drug-nanotube” hybrids.

data obtained for hormone-like inhibitors tested in vivo on heartbeat frequency in insects suggested adaptation of cellular receptors at low concentrations of peptide leucomyosuppressin (for low heartbeat frequency, the inhibition was observed) and further their resistance at higher concentrations (at higher heartbeat frequency, no inhibition was observed) [59]. A similar phenomenon called hormesis is frequently found in the radiosensitivity or radioresistance assays where low doses of ionizing radiation are more toxic than higher ones, because of cancer cells adaptation to the toxic conditions at higher doses of IR [60]. Also, for starshaped copolymers as nanocarriers of bioactive compounds tested on MCF-7 and MCF-7 doxorubicin-resistant cell lines, bimodal activities were observed: cytotoxicity decreased with the increasing concentrations [61].

Apoptosis induced by nanotube vehicles and (preselected in the MTS assay) most cytotoxic hybrids was analyzed using an Annexin V assay (Figure 6). The results were presented in the background of pure anticancer agents (and their prodrug counterparts).

It is evident (Figure 6(a)) that the MWCNT $>$ N-5FU (3ab) hybrid is characterized by the lowest tendency to induce necrosis in Me45. This behavior is in contrast to pure 5FU $(\mathbf{2 g})$ and $5 \mathrm{FU}-\mathrm{N}_{3}(\mathbf{2 b})$. Similar tendency could be found for the MWCNT>N-Purp (3aa) of which cytotoxicity was based on the activation of apoptosis (Figure 6(b)). Oppositely, $3 \mathbf{b f}$ hybrid induced necrosis in the highest fraction of Caco-2 population (Figure 6(c)). Obviously, in this context, MWCNT $>$ N-5FU (3ab) and MWCNT>N-Purp (3aa) emerge as the most promising hybrids against Me45 and HCT116+ cells, respectively.

Analysis of the cell life cycles in the presence of nanotubes, drugs, and "drug-nanotube" hybrids was based on the determination of the cellular DNA content using propidium iodide (PI) and flow cytometry as a technique (Figure 7).
The aim of the analysis, as a natural continuation of the above apoptosis studies, was to determine which phase of the cell division is impaired or inhibited by the most promising "drug-nanotube" hybrids.

As PI binds stoichiometrically to DNA; the number of DNA-PI complexes enables calculating histograms of DNA contents as a function of fluorescence intensity of the dye for nanotube vehicles, pure drugs, and "drug-nanotube" hybrids. Four main phases of the cell division $[62,63]$ could be observed here: sub-G1, G0/G1, S, and G2/M. The G2/M phase determines mitosis (in which the cell contains a double amount of DNA as before division, i.e., in the G0/G1 phase). The cells, described by phase sub-G1 in which DNA content is lower than in the G0/G1 phase, correspond to apoptotic and necrotic cells. Divided cells are in the $S$ fraction. The level of polyploids (cells containing more DNA than in the G2/M phase) is typically referred to as noise and indicates damage that occurred during mitosis [64]. As shown, the results are in the agreement with the apoptosis and cytotoxicity studies. All of the hybrids generated mostly apoptotic cells as a response. On the other hand, the presence of apoptotic cells does not exclude the possibility of cellular membrane damage while this effect can be significantly enhanced in the presence of a magnetic field.

\section{Conclusions}

In the quest for novel targeted drug delivery systems, "drugMWCNT" hybrids were synthesized and their biological activity was determined in vitro against selected cancer cell lines. Nanotubes themselves, as vehicles enhancing targeting and revealing its intrinsic cytotoxicity, may be considered as potential platforms in the magnetic drug delivery. The earlier observed magnetic maneuverability [42] was here confirmed by Mössbauer spectroscopy which indicated the presence of 

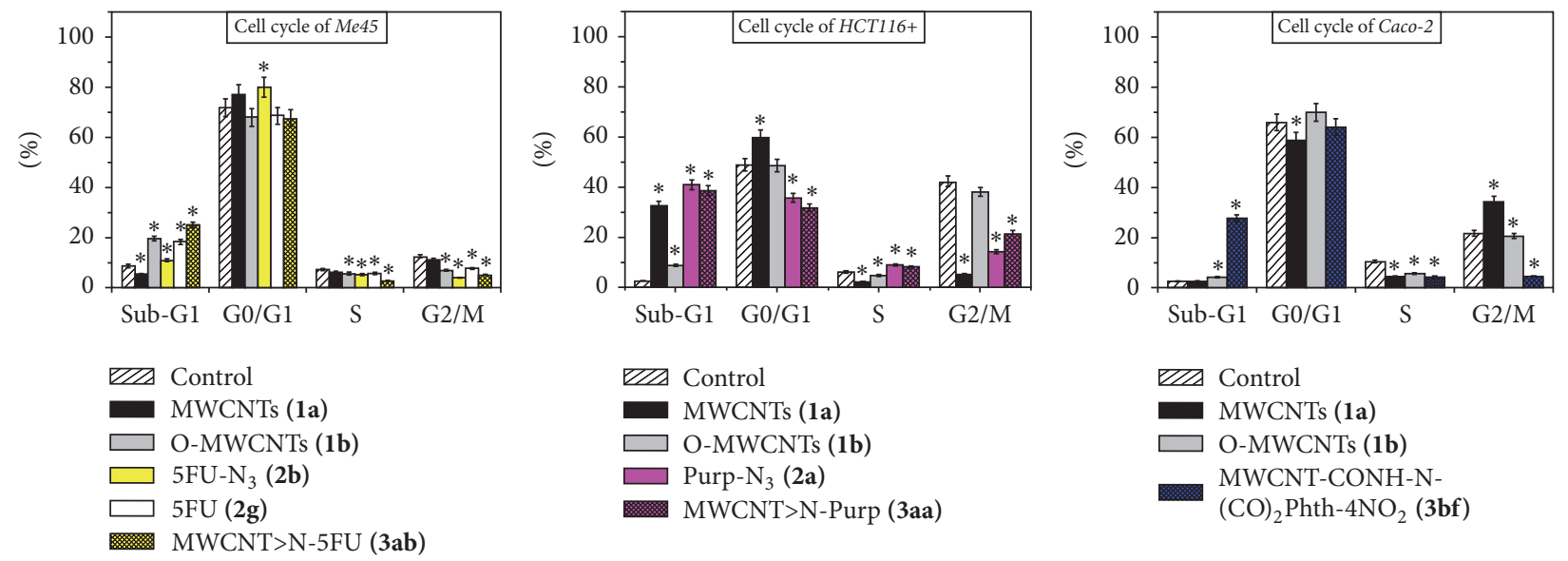

Figure 7: Analysis of the cell cycle in Me45, HCT116+, and Caco-2 lines incubated with MWCNT vehicles, drugs/prodrugs, and "drugnanotube" hybrids.

ferromagnetic Fe-based phases encapsulated in the core of nanotubes, also at a sufficient level in oxidized nanotubes. Their application however must be carefully addressed as different cancer cells reveal different levels of sensitivity to the "drug-nanotube" hybrids. Fe@MWCNT hybrids of 5FU and Purp, formed via nitrene chemistry, appear as the most suitable rapid response magnetic drug delivery systems in the locoregional therapy against Me45 and HCT116+ cells, while hybrids of oxidized Fe@MWCNTs and 4-nitro- and 4-(Nmorpholinyl)-1,8-naphthalimide DNA intercalator formed via amidation against Caco- 2 cells. The studies open a route to in vivo research against the so-preselected cancer cells exploiting hybrids of Fe@MWCNTs and anticancer agents formed via novel surface chemistries.

\section{Experimental}

SEM analysis was performed by means of SEM JEOL 7001TTLS. High-resolution transmission electron microscopy micrographs were obtained with a JEOL ARM 200F HRTEM with an accelerating voltage of $200 \mathrm{kV}$. The Raman spectra were obtained using a Ramascope-1000 spectrometer. The excitation source was a He-Ne laser of a wavelength of $633 \mathrm{~nm}$. Each spectrum was collected with six accumulations of $10 \mathrm{~s}$. Mössbauer transmission measurements were performed at room temperature using RENON MsAa-3 spectrometer equipped with the LND Kr-filled proportional detector and He-Ne laser-based interferometer used to calibrate velocity scale [65]. A commercial ${ }^{57} \mathrm{Co}(\mathrm{Rh})$ source kept at room temperature was applied for $14.41 \mathrm{keV}$ resonant transition in ${ }^{57} \mathrm{Fe}$. The Mössbauer absorbers were prepared using 100 mg of Fe@MWCNTs or Fe@O-MWCNTs and the absorbers' thicknesses amounted to $50 \mathrm{mg} / \mathrm{cm}^{2}$. Data were processed by means of the Mosgraf-2009 software within the transmission integral approximation.

4.1. Stock Solutions/Dispersions. Pure compounds were introduced into media as solutions in DMSO (99.9\%) and their cytotoxicity was determined for eleven concentrations, that is, $1 \mathrm{ng} / \mathrm{mL}, 5 \mathrm{ng} / \mathrm{mL}, 25 \mathrm{ng} / \mathrm{mL}, 50 \mathrm{ng} / \mathrm{mL}, 100 \mathrm{ng} / \mathrm{mL}$, $500 \mathrm{ng} / \mathrm{mL}, 1 \mu \mathrm{g} / \mathrm{mL}, 10 \mu \mathrm{g} / \mathrm{mL}, 25 \mu \mathrm{g} / \mathrm{mL}, 50 \mu \mathrm{g} / \mathrm{mL}$, and $100 \mu \mathrm{g} / \mathrm{mL}$. In order to obtain the appropriate concentrations, $1 \mathrm{mg}$ of each compound was dissolved in DMSO $(1 \mathrm{~mL})$, and the mother solution $(1 \mathrm{mg} / \mathrm{mL})$ was used as a base for the more diluted solutions. Each solution was filtered through a $22 \mu \mathrm{m}$ filter.

Cytotoxicity of nanotube vehicles and drug-nanotube hybrids was determined for dispersions of four concentrations, that is, $5,10,20$, and $50 \mu \mathrm{g} / \mathrm{mL}$. Similarly, as for pure compounds, firstly, the mother dispersion of $1 \mathrm{mg} / \mathrm{mL}$ was prepared by $1 \mathrm{~h}$ of ultrasonication at $37^{\circ} \mathrm{C}$, and then diluted and ultrasonicated dispersions were prepared and introduced into the media.

4.2. Cell Lines. Three cell lines were used in the studies, namely, Me45, HCT116+, and Caco-2. The first cell line is human fibroblasts derived from malignant melanoma. The two other epithelial lines derive from human colon cancer. All of the cells are characterized by the adherent growth mode. Human melanoma (Me45) cell line was derived in 1997 from melanoma metastasis to lymph node of a 35year-old male patient treated at the Institute of Radiobiology of the Maria Skłodowska-Curie Memorial Cancer Centre, Gliwice (Poland). Human colon carcinoma (HCT116+) cell line is a line of human colon adenoma cells. The cells were grown in the bank of Maria Skłodowska-Curie Memorial Cancer Centre, Gliwice (Poland). Human Caucasian colon adenocarcinoma (Caco-2) cell line was isolated from a 72year-old Caucasian male. The line was purchased from the European Collection of Cell Cultures (ECACC) and the line was generously given by the Medical University of Silesia in Zabrze (Poland). The cells are of high resemblance to the human intestinal epithelium cells. It must be emphasized that Caco-2, as the only one from all of the cell lines previously derived from the intestinal tumor line, is capable of forming a layer of cells possessing morphological, structural, and functional similarity to the intestinal epithelium occurring in the human body. Key features characterizing Caco- 2 cells are 
(a) formation of intercellular tight junctions, (b) expression of specific enzymes, for example, alkaline phosphatase or protein transport channels (P-glycoprotein, cytochromes, etc.), and (c) cell differentiation towards the formation of microvilli of the "brush border."

4.3. Cell Cultures. All cell lines were cultured in culture flasks with $25 \mathrm{~cm}^{2}$ (T-25) or $75 \mathrm{~cm}^{2}$ (T-75) bottom surface. Basic medium DMEM/Ham's F-12 with L-glutamine was supplemented with Fetal Bovine Serum (FBS) (12\%) containing antibiotics MycoKill AB (1:50 dilution). The culture was grown in an incubator under standard conditions, that is, $37^{\circ} \mathrm{C}, \mathrm{CO}_{2}$ content in the atmosphere of $5 \%$, and humidity of ca. $60 \%$.

4.4. Passage and Culture of Cells. Under sterile conditions, the stale medium was poured from the above cell cultures. The bottom of the bottle was washed with 1 or $3 \mathrm{~mL}$ of a concentrated solution of trypsin, for T-25 or T-75 bottles, respectively, in order to neutralize the trypsin present in the culture medium and to remove dead cells only slightly adhering to the bottom of the bottles. Then, $3 \mathrm{~mL}$ (T-25) or $5 \mathrm{~mL}$ (T-75) of a freshly prepared concentrated solution of trypsin was added to the bottles using a serological pipette and the bottles were placed in the incubator for a few minutes. The process of separation of cells was continuously monitored under a light microscope. The duration of the process varied and depended on the adhesion degree of cells to the substrate and morphology of the cells (in the case of HCT116+ and Caco- 2 cells, the process was rapid, whereas Me45 cells were detaching very slowly). After complete detachment of the cells, an equal amount ( 3 or $5 \mathrm{~mL}$ ) of the fresh culture medium was added to the bottle. The bottle's content was carefully divided using a serological pipette, transferred to Falcon tubes, and then centrifuged in a bench centrifuge $(1500 \mathrm{rpm}$, $3 \mathrm{~min})$. The medium with trypsin was carefully decanted from the cell sediment, and then $1 \mathrm{~mL}$ of fresh medium was added again. After precise distribution of the cell sediments in the new medium, ca. $100 \mu \mathrm{L}$ of suspension was collected in an Eppendorf tube in order to count the number of cells in the Bürker counting chamber. After the passage, the bottle was refilled with fresh culture medium DMEM (8-9 mL T-25) and (10-12 mL T-75) and the growth of cells was continued.

After determination of concentration of cells per $1 \mathrm{~mL}$ of suspension, the appropriate volume of suspension was withdrawn to a new test tube and filled up with fresh DMEM medium, depending on the volume required for the planned assay.

4.5. Cytotoxicity Assays. The cells were trypsinized, counted in the Bürker chamber, suspended in a suitable amount of DMEM medium, and then placed in 96-well plates, which were then cultured for $24 \mathrm{~h}$ under standard conditions $\left(37^{\circ} \mathrm{C}, 5 \% \mathrm{CO}_{2}\right)$. After $24 \mathrm{~h}$, the medium was removed and replaced with a fresh one of volume allowing for dosing solutions/dispersions of tested compounds, nanotube vehicles, "drug-nanotube" hybrids, and the control of the appropriate concentration. Each measurement was performed in triplicate.
After the addition of media and solutions/dispersions, the plates were incubated for $24 \mathrm{~h}$ under standard conditions. Then, the medium was removed from above the cells and was replaced by $100 \mu \mathrm{L}$ of phosphate-buffered saline (PBS). The MTS reagent was combined with 1-methoxyphenazine methosulfate (PMS) $(2 \mathrm{~mL}$ MTS $+100 \mu \mathrm{L}$ PMS for each plate) and $20 \mu \mathrm{L}$ of the mixture was added to each well. The plates were incubated for $2 \mathrm{~h}$ until the color in the control wells was changed from light yellow to brown. The absorbance for formazan produced solely by alive cells was measured at a wavelength of $\lambda=490 \mathrm{~nm}$ using a microplate spectrophotometer. The absorbance values were expressed as a percentage change in viability of tested cells relative to the control cells. Cell viability was therefore calculated from the formula cell viability $=A / A_{0} \cdot 100 \%$.

4.6. Analysis of Apoptosis. After removal of cells, trypsin was neutralized with the previously collected medium. The samples were centrifuged (1500 rpm, $3 \mathrm{~min}$ ) and the supernatant was carefully removed using a pipette. The precipitate was washed with $300 \mu \mathrm{L}$ of PBS and, to the rinsed precipitate of cells, cold Annexin-dedicated buffer $(50 \mu \mathrm{L})$ and then Annexin V $(2.5 \mu \mathrm{L})$ were added. Next, the open tubes were placed into the incubator for $20 \mathrm{~min}$. After this time, $250 \mu \mathrm{L}$ of Annexin-dedicated buffer and $10 \mu \mathrm{L}$ of PI solution $(3 \mathrm{mg} / \mathrm{mL})$ were added and the whole system was mixed carefully. The samples were incubated in the dark for $15 \mathrm{~min}$ and then transferred onto ice. Immediately prior to the flow cytometric analysis, the samples were vortexed and transferred to cytometer tubes. The counting camera encountered first 10,000 events. The results were analyzed using Flowing MS Office $^{\circledR}$ ver. 2.5.0 and MS Excel 2007 ${ }^{\circledR}$.

4.7. Cell Cycle Analysis by Flow Cytometry. After addition of the appropriate amounts of medium and solutions/dispersions, the samples were incubated for $24 \mathrm{~h}$ under standard conditions. Afterwards, the medium was moved to new Eppendorf tubes, whereas the remaining cells were detrypsinized (by adding $500 \mu \mathrm{L}$ of concentrated trypsin solution to each well). Trypsin was neutralized by previously poured off medium containing dead cells and the samples were centrifuged $(1500 \mathrm{rpm}, 3 \mathrm{~min})$. The supernatant was carefully poured off, and the precipitate was rinsed with $300 \mu \mathrm{L}$ of PBS. Then, to each tube, $600 \mu \mathrm{L}$ of frozen $96 \%$ $\mathrm{EtOH}$ was added dropwise and the tubes were vortexed for the accurate fixation of the cells. The samples were stored at $4^{\circ} \mathrm{C}$ for a minimum of $24 \mathrm{~h}$, and up to a week and before the measurements, they were again centrifuged $(1000 \mathrm{rpm}$, $3 \mathrm{~min}$ ). The supernatant was collected and the residual cells were rinsed with $300 \mu \mathrm{L}$ of PBS. Then, $50 \mu \mathrm{L}$ of RNase solution at a concentration of $100 \mu \mathrm{g} / \mathrm{mL}$ (prepared from a stock solution of $10 \mathrm{mg} / \mathrm{mL}$, in a ratio of $1: 49 \mathrm{RNase} / \mathrm{PBS}$ ) was added in order to remove RNA and the samples were shaken in a Thermoblock at $37^{\circ} \mathrm{C}$ for $20 \mathrm{~min}$. Then, $250 \mu \mathrm{L}$ of PI was added at a concentration of $100 \mu \mathrm{g} / \mathrm{mL}$ and the samples were allowed to stand in the dark for $10 \mathrm{~min}$. After this time, the samples were transferred onto ice. Immediately prior to the measurements, each sample was vortexed thoroughly and the tube was placed in a flow cytometer. The counting camera 
encountered first 10,000 events. The results were presented as the number of cells histograms of fluorescence intensity versus concentration of PI and then analyzed by Flowing MS Office 2.5.0 and MS Excel 2007.

4.8. Statistical Analysis. All measurements for cytotoxicity, apoptosis, and cell cycle were performed at least in triplicate, and results were presented as average $+/-$ SD. The significance of any changes, according to the control and untreated cells, was calculated with Student's $t$-test with $p$ value $<0.001$. Relevant changes presented in Figures 5-7 were indicated by an asterisk $(*)$.

4.9. Preparation of the Samples for Microscopy Imaging. The sample preparation for microscopic analysis lasted $72 \mathrm{~h}$. Firstly, cell trypsinization was performed, the amount of cells was determined using a Bürker chamber, and the samples were prepared in a suitable suspension. The cells were placed onto sterile 4-well plates and incubated for $24 \mathrm{~h}$ under standard conditions. Subsequently, DMEM was replaced by a freshly prepared one, in order to maintain concentration of the hybrids. Images were acquired for concentrations of 5 and $50 \mu \mathrm{g} / \mathrm{mL}$. After addition of appropriate amounts of medium and solution/dispersion, the samples were incubated for $24 \mathrm{~h}$ under standard conditions. Then, the supernatant was carefully collected with a pipette from the cells and discarded. The cells were washed with $500 \mu \mathrm{L}$ of PBS and then fixed with $70 \%$ $\mathrm{EtOH}(10 \mathrm{~min})$. After fixation, alcohol was removed, $500 \mu \mathrm{L}$ of deionized water was added, and the system was allowed to stand for 2-3 min. Subsequently, water was removed with a pipette and the wall plate was broken off. To each well, $10 \mu \mathrm{L}$ of DAPI was introduced and a drop of glycerol was added, and then the well was covered with a coverslip, which was then protected against drying using a dedicated resin. The samples were stored in closed boxes at $4^{\circ} \mathrm{C}$.

\section{Conflicts of Interest}

The authors declare that there are no conflicts of interest regarding the publication of this paper.

\section{Acknowledgments}

Sławomir Boncel, Artur P. Herman, and Rafał G. Jędrysiak would like to thank the National Science Centre in Poland (Program SONATA, 2012/05/D/ST5/03519) for the financial support. The authors are grateful to Professor Julita MrowiecBiałoń and Dr. Katarzyna Maresz for TG analyses and the insightful discussions.

\section{References}

[1] R. L. Siegel, K. D. Miller, and A. Jemal, "Cancer statistics, 2016," CA: A Cancer Journal for Clinicians, vol. 66, no. 1, pp. 7-30, 2016.

[2] A. Schroeder, D. A. Heller, M. M. Winslow et al., "Treating metastatic cancer with nanotechnology," Nature Reviews Cancer, vol. 12, no. 1, pp. 39-50, 2012.

[3] World Health Organization, World Cancer Report 2014, chapter 1.1, 2014.
[4] A. P. Nikalje, "Nanotechnology and its applications in medicine," Medicinal Chemistry, vol. 5, no. 2, pp. 81-89, 2015.

[5] A. Hafner, J. Lovrić, G. P. Lakǒ, and I. Pepić, "Nanotherapeutics in the EU: An overview on current state and future directions," International Journal of Nanomedicine, vol. 9, no. 1, article no. 1005, pp. 1005-1023, 2014.

[6] K. Ulbrich, K. Holá, V. Šubr, A. Bakandritsos, J. Tuček, and R. Zbořil, "Targeted drug delivery with polymers and magnetic nanoparticles: covalent and noncovalent approaches, release control, and clinical studies," Chemical Reviews, vol. 116, no. 9, pp. 5338-5431, 2016.

[7] J. Gautier, E. Allard-Vannier, J. Burlaud-Gaillard, J. Domenech, and I. Chourpa, "Efficacy and hemotoxicity of stealth doxorubicin-loaded magnetic nanovectors on breast cancer xenografts," Journal of Biomedical Nanotechnology, vol. 11, no. 1, pp. 177-189, 2015.

[8] J. Lee, H. Kim, S. Kim et al., "A multifunctional mesoporous nanocontainer with an iron oxide core and a cyclodextrin gatekeeper for an efficient theranostic platform," Journal of Materials Chemistry, vol. 22, no. 28, pp. 14061-14067, 2012.

[9] H.-L. Liu, M.-Y. Hua, H.-W. Yang et al., "Magnetic resonance monitoring of focused ultrasound/magnetic nanoparticle targeting delivery of therapeutic agents to the brain," Proceedings of the National Academy of Sciences of the United States of America, vol. 107, no. 34, pp. 15205-15210, 2010.

[10] V. Aran, A. P. Victorino, L. C. Thuler, and C. G. Ferreira, "Colorectal cancer: epidemiology, disease mechanisms and interventions to reduce onset and mortality," Colorectal Cancer, vol. 15, pp. 195-203, 2016.

[11] A. H. Shain and B. C. Bastian, "From melanocytes to melanomas," Nature Reviews Cancer, vol. 16, no. 6, pp. 345-358, 2016.

[12] P. S. Steeg, “Targeting metastasis," Nature Reviews Cancer, vol. 16, pp. 201-218, 2016.

[13] G. P. Tuszynski and G. Cossu, "Differential cytotoxic effect of gossypol on human melanoma, colon carcinoma, and other tissue culture cell lines," Cancer Research, vol. 44, pp. 768-771, 1984.

[14] V. Amenta and K. Aschberger, "Carbon nanotubes: Potential medical applications and safety concerns," Wiley Interdisciplinary Reviews: Nanomedicine and Nanobiotechnology, vol. 7, no. 3, pp. 371-386, 2015.

[15] S. Y. Madani, A. Mandel, and A. M. Seifalian, "A concise review of carbon nanotube's toxicology," Nano Reviews, vol. 4, no. 1, Article ID 21521, 2013.

[16] http://bio-pact.com/mgmr/.

[17] S. Boncel, K. H. Müller, J. N. Skepper, K. Z. Walczak, and K. K. K. Koziol, "Tunable chemistry and morphology of multi-wall carbon nanotubes as a route to non-toxic, theranostic systems," Biomaterials, vol. 32, no. 30, pp. 7677-7686, 2011.

[18] H. Ali-Boucetta, A. Nunes, R. Sainz et al., "Asbestos-like pathogenicity of long carbon nanotubes alleviated by chemical functionalization," Angewandte Chemie, vol. 52, no. 8, pp. 22742278, 2013.

[19] V. E. Kagan, A. A. Kapralov, C. M. St Croix et al., "Lung macrophages Digest carbon nanotubes using a superoxide/ peroxynitrite oxidative pathway," ACS Nano, vol. 8, no. 6, pp. 5610-5621, 2014.

[20] J. Russier, C. Ménard-Moyon, E. Venturelli et al., "Oxidative biodegradation of single- and multi-walled carbon nanotubes," Nanoscale, vol. 3, no. 3, pp. 893-896, 2011. 
[21] K. Bhattacharya, C. Sacchetti, R. El-Sayed et al., "Enzymatic 'stripping' and degradation of PEGylated carbon nanotubes," Nanoscale, vol. 6, no. 24, pp. 14686-14690, 2014.

[22] C. Fabbro, H. Ali-Boucetta, T. D. Ros, K. Kostarelos, A. Bianco, and M. Prato, "Targeting carbon nanotubes against cancer," Chemical Communications, vol. 48, no. 33, pp. 3911-3926, 2012.

[23] E. Pérez-Herrero and A. Fernández-Medarde, "Advanced targeted therapies in cancer: drug nanocarriers, the future of chemotherapy," European Journal of Pharmaceutics and Biopharmaceutics, vol. 93, pp. 52-79, 2015.

[24] Y. Kim, O. N. Torrens, J. M. Kikkawa, E. Abou-Hamad, C. Goze-Bac, and D. E. Luzzi, "High-purity diamagnetic singlewall carbon nanotube buckypaper," Chemistry of Materials, vol. 19, no. 12, pp. 2982-2986, 2007.

[25] S. Boncel, A. P. Herman, and K. Z. J. Walczak, "Magnetic carbon nanostructures in medicine," Journal of Materials Chemistry, vol. 22, pp. 31-37, 2012.

[26] A. Al Faraj, A. P. Shaik, and A. S. Shaik, "Magnetic singlewalled carbon nanotubes as efficient drug delivery nanocarriers in breast cancer murine model: Noninvasive monitoring using diffusion-weighted magnetic resonance imaging as sensitive imaging biomarker," International Journal of Nanomedicine, vol. 10, pp. 157-168, 2014.

[27] A. M. A. Elhissi, W. Ahmed, I. U. Hassan, V. R. Dhanak, and A. D'Emanuele, "Carbon nanotubes in cancer therapy and drug delivery," vol. 2012, Article ID 837327, 10 pages, 2012.

[28] X. Fan and X. Li, "Preparation and magnetic property of multiwalled carbon nanotubes decorated by $\mathrm{Fe}_{3} \mathrm{O}_{4}$ nanoparticles," New Carbon Mater, vol. 27, pp. 111-116, 2012.

[29] B. M. Maciejewska, L. E. Coy, K. K. K. Koziol, and S. Jurga, "Facile synthesis of highly stable and water-soluble magnetic MWCNT/ $\alpha$-Fe nanocomposites," Journal of Physical Chemistry C, vol. 118, no. 48, pp. 27861-27869, 2014.

[30] S. K. Vashist, D. Zheng, G. Pastorin, K. Al-Rubeaan, J. H. T. Luong, and F.-S. Sheu, "Delivery of drugs and biomolecules using carbon nanotubes," Carbon, vol. 49, no. 13, pp. 4077-4097, 2011.

[31] W. Zhang, Z. Zhang, and Y. Zhang, "The application of carbon nanotubes in target drug delivery systems for cancer therapies," Nanoscale Research Letters, vol. 6, no. 555, 2011.

[32] A. A. Bhirde, V. Patel, J. Gavard et al., "Targeted killing of cancer cells in vivo and in vitro with EGF-directed carbon nanotubebased drug delivery," ACS Nano, vol. 3, no. 2, pp. 307-316, 2009.

[33] N. M. Dinan, F. Atyabi, M.-R. Rouini, M. Amini, A.-A. Golabchifar, and R. Dinarvand, "Doxorubicin loaded folatetargeted carbon nanotubes: Preparation, cellular internalization, in vitro cytotoxicity and disposition kinetic study in the isolated perfused rat liver," Materials Science and Engineering $C$, vol. 39, no. 1, pp. 47-55, 2014.

[34] Y. Yu, L. Kong, L. Li, N. Li, and P. Yan, "Antitumor activity of doxorubicin-loaded carbon nanotubes incorporated poly(lactic-co-glycolic acid) electrospun composite nanofibers," Nanoscale Research Letters, vol. 10, no. 343, 2015.

[35] P. Das, C. K. Jain, S. K. Dey et al., "Synthesis, crystal structure, DNA interaction and in vitro anticancer activity of a $\mathrm{Cu}(\mathrm{ii})$ complex of purpurin: Dual poison for human DNA topoisomerase i and II," RSC Advances, vol. 4, no. 103, pp. 59344-59357, 2014.

[36] J. K. Son, S. J. Jung, J. H. Jung et al., "Anticancer constituents from the roots of Rubia cordifolia L.," Chemical and Pharmaceutical Bulletin, vol. 56, no. 2, pp. 213-216, 2008.
[37] O. Tacar, P. Sriamornsak, and C. R. Dass, "Doxorubicin: an update on anticancer molecular action, toxicity and novel drug delivery systems," Journal of Pharmacy and Pharmacology, vol. 65 , no. 2, pp. 157-170, 2013.

[38] D. B. Longley, D. P. Harkin, and P. G. Johnston, "5-Fluorouracil: mechanisms of action and clinical strategies," Nature Reviews Cancer, vol. 3, no. 5, pp. 330-338, 2003.

[39] J. Mehrotra, K. Misra, and R. K. Mishra, "Dna intercalation and photoinduced cleavage by 4-nitro(n-hexylamine)1,8naphthalimide," Nucleosides and Nucleotides, vol. 13, no. 4, pp. 963-978, 1994.

[40] M. F. Braña and A. Ramos, "Naphthalimides as anti-cancer agents: synthesis and biological activity," Current Medicical Chemistry Anticancer Agents, vol. 1, no. 3, pp. 237-255, 2001.

[41] W. Zhang, X. Qian, Y. Wu, and H. Ohrui, "A new class of dna intercalator and photocleaver: bis-naphthalimides with bromo and nitro substituents," Heterocyclic Communications, vol. 9, pp. 229-234, 2011.

[42] S. Boncel, A. P. Herman, S. Budniok et al., "In vitro targeting and selective killing of T47D breast cancer cells by purpurin and 5-fluorouracil anchored to magnetic CNTs: nitrene-based functionalization versus uptake, cytotoxicity, and intracellular fate," ACS Biomaterials Science and Engineering, vol. 2, no. 8, pp. 1273-1285, 2016.

[43] S. Boncel, S. W. Pattinson, V. Geiser, M. S. P. Shaffer, and K. K. K. Koziol, "En route to controlled catalytic CVD synthesis of densely packed and vertically aligned nitrogen-doped carbon nanotube arrays," Beilstein Journal of Nanotechnology, vol. 5, no. 1, pp. 219-233, 2014.

[44] S. Boncel, K. K. K. Koziol, K. Z. Walczak, A. H. Windle, and M. S. P. Shaffer, "Infiltration of highly aligned carbon nanotube arrays with molten polystyrene," Materials Letters, vol. 65, no. 14, pp. 2299-2303, 2011.

[45] M. S. Dresselhaus, A. Jorio, A. G. S. Filho, and R. Saito, "Defect characterization in graphene and carbon nanotubes using Raman spectroscopy," Philosophical Transactions of the Royal Society A, vol. 368, no. 1932, pp. 5355-5377, 2010.

[46] S. Boncel, M. Brzeziński, J. Mrowiec-Białoń, D. Janas, K. K. K. Koziol, and K. Z. Walczak, "Oxidised multi-wall carbon nanotubes-(R)-polylactide composite with a covalent $\beta$-duridine filler-matrix linker," Materials Letters, vol. 91, pp. 50-54, 2013.

[47] J. F. Marco, J. R. Gancedo, A. Hernando et al., "Mössbauer study of iron-containing carbon nanotubes," Hyperfine Interactions, vol. 139-140, no. 1-4, pp. 535-542, 2002.

[48] A. Jamrozik, M. Mazurkiewicz, A. Małolepszy et al., "Mössbauer spectroscopy analysis of iron compounds in carboxylated multiwall carbon nanotubes and their ammonium salt," Physica Status Solidi (A) Applications and Materials Science, vol. 208, no. 8, pp. 1783-1786, 2011.

[49] K. K. K. Koziol, C. Ducati, and A. H. Windle, "Carbon nanotubes with catalyst controlled chiral angle," Chemistry of Materials, vol. 22, no. 17, pp. 4904-4911, 2010.

[50] S. Boncel, D. Osyda, and K. Z. Walczak, "N-1 regioselective Michael-type addition of 5-substituted uracils to (2-hydroxyethyl) acrylate," Beilstein Journal of Organic Chemistry, vol. 3, article 40, 2007.

[51] E. C. Vermisoglou, G. Pilatos, G. E. Romanos, E. Devlin, N. K. Kanellopoulos, and G. N. Karanikolos, "Magnetic carbon nanotubes with particle-free surfaces and high drug loading capacity," Nanotechnology, vol. 22, no. 35, Article ID 355602, 2011. 
[52] J. M. Tan, G. Karthivashan, P. Arulselvan, S. Fakurazi, and M. Z. Hussein, "Characterization and in vitro studies of the anticancer effect of oxidized carbon nanotubes functionalized with betulinic acid," Drug Design, Development and Therapy, vol. 8, pp. 2333-2343, 2014.

[53] S. Hu, T. Wang, X. Pei et al., "Synergistic enhancement of antitumor efficacy by PEGylated multi-walled carbon nanotubes modified with cell-penetrating peptide TAT," Nanoscale Research Letters, vol. 11, p. 452, 2016.

[54] S. Y. Madani, A. Tan, M. Dwek, and A. M. Seifalian, "Functionalization of single-walled carbon nanotubes and their binding to cancer cells," International Journal of Nanomedicine, vol. 7, pp. 905-914, 2012.

[55] M. Mahmood, Y. Xu, V. Dantuluri et al., "Carbon nanotubes enhance the internalization of drugs by cancer cells and decrease their chemoresistance to cytostatics," Nanotechnology, vol. 24, no. 4, Article ID 045102, 2013.

[56] S. Alarifi, D. Ali, A. Verma, F. N. Almajhdi, and A. A. AlQahtani, "Single-walled carbon nanotubes induce cytotoxicity and DNA damage via reactive oxygen species in human hepatocarcinoma cells," In Vitro Cellular and Developmental Biology - Animal, vol. 50, no. 8, pp. 714-722, 2014.

[57] E. Roda, A. F. Castoldi, T. Coccini et al., "In vitro toxicity assessment of single- and multi-walled carbon nanotubes in human astrocytoma and lung carcinoma cells," Toxicology Letters, vol. 172, pp. S235-S236, 2007.

[58] O. Vittorio, V. Raffa, and A. Cuschieri, "Influence of purity and surface oxidation on cytotoxicity of multiwalled carbon nanotubes with human neuroblastoma cells," Nanomedicine: Nanotechnology, Biology and Medicine, vol. 5, pp. 424-431, 2009.

[59] O. Wasielewski and M. Skonieczna, "Pleiotropic effects of the neuropeptides CCAP and myosuppressin in the beetle, Tenebrio molitor L.," Journal of Comparative Physiology B: Biochemical, Systemic, and Environmental Physiology, vol. 178, no. 7, pp. 877-885, 2008.

[60] J. Cui, G. Yang, Z. Pan et al., "Hormetic response to lowdose radiation: focus on the immune system and its clinical implications," International Journal of Molecular Sciences, vol. 18, no. 2, 280 pages, 2017.

[61] A. Mielańczyk, M. Skonieczna, Ł. Mielańczyk, and D. Neugebauer, "In vitro evaluation of doxorubicin conjugates based on sugar core nonlinear polymethacrylates toward anticancer drug delivery," Bioconjugate Chemistry, vol. 27, no. 4, pp. 893-904, 2016.

[62] P. Pozarowski and Z. Darzynkiewicz, "Analysis of cell cycle by flow cytometry," in Checkpoint Controls and Cancer, A. H. Schönthal, Ed., vol. 281 of Methods in Molecular Biology, pp. 301-311, Humana Press, NJ, USA, 2004.

[63] M. G. J. Ormerod, "Investigating the relationship between the cell cycle and apoptosis using flow cytometry," Journal of Immunological Methods, vol. 265, pp. 73-80, 2002.

[64] P. Capella and J. Moll, "Assessment of cell cycle inhibitors by flow cytometry," in Drug Discovery and Development-Present and Future, vol. 13, pp. 323-338, 2011.

[65] R. Górnicki, A. Błachowski, and K. Ruebenbauer, "Mössbauer Spectrometer MsAa-3," Nukleonika, vol. 52, supplement 1, pp. S7-S12, 2007. 

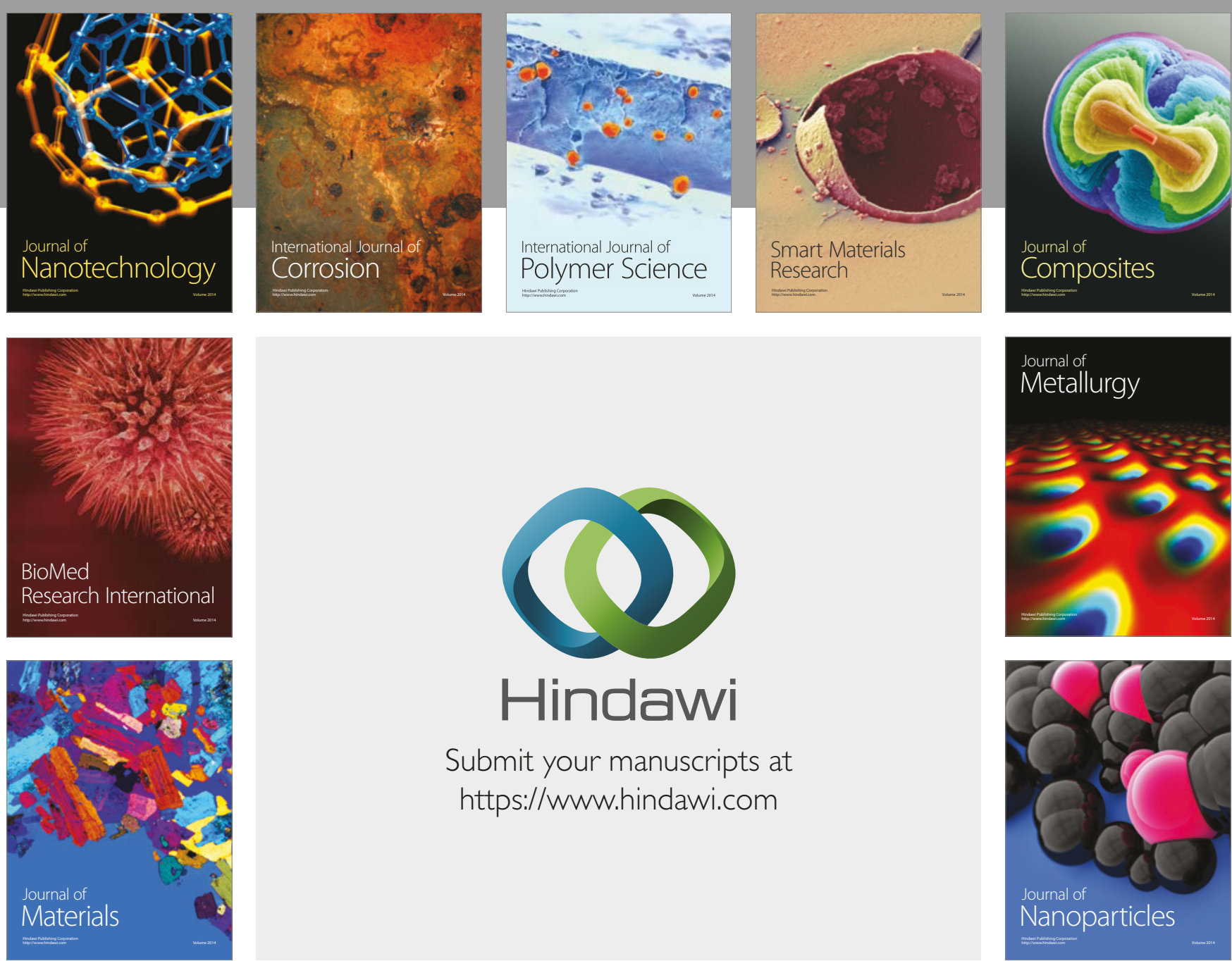

\section{Hindawi}

Submit your manuscripts at

https://www.hindawi.com
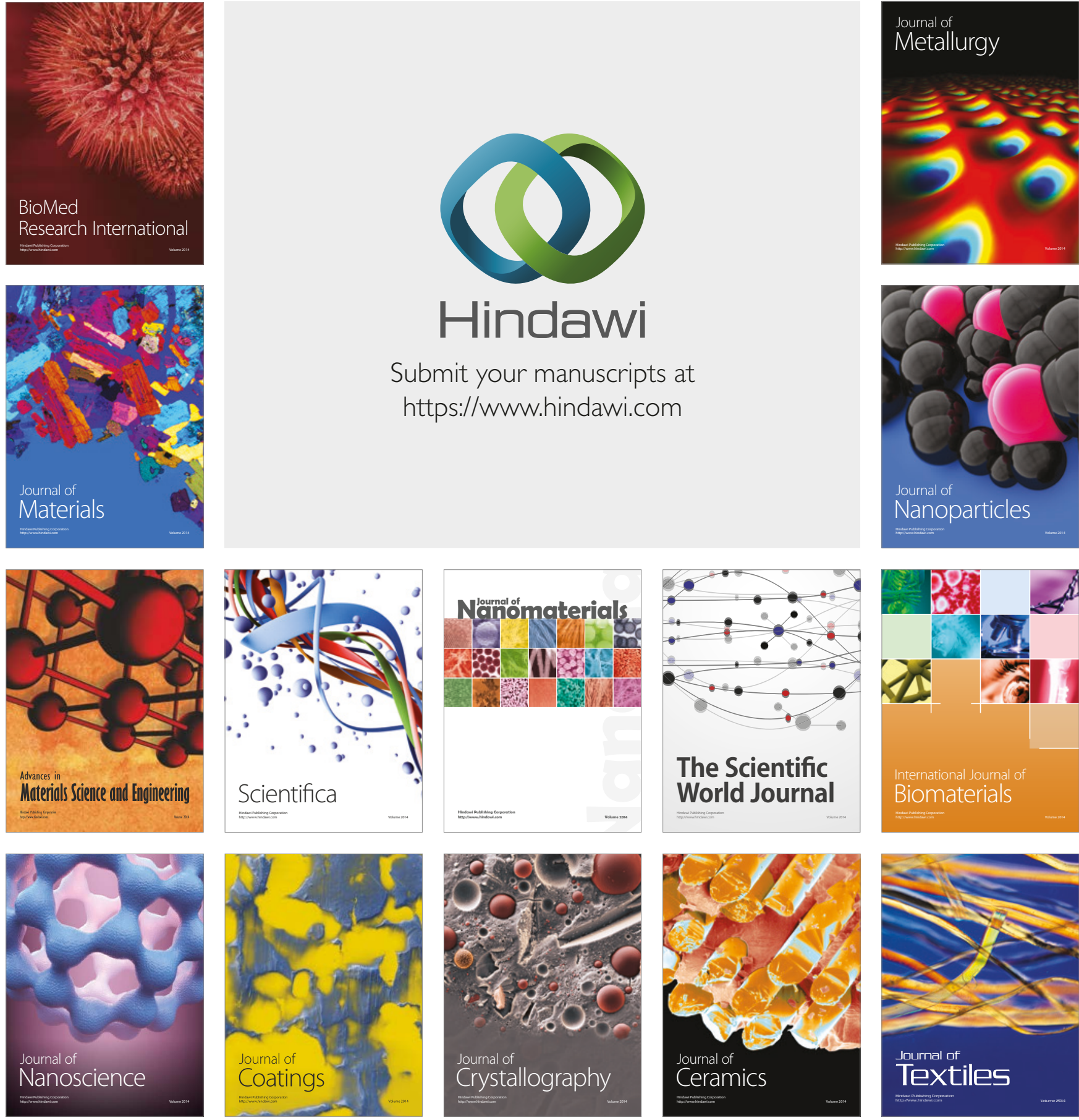

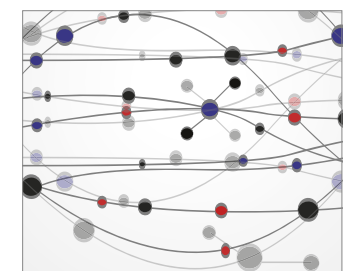

The Scientific World Journal
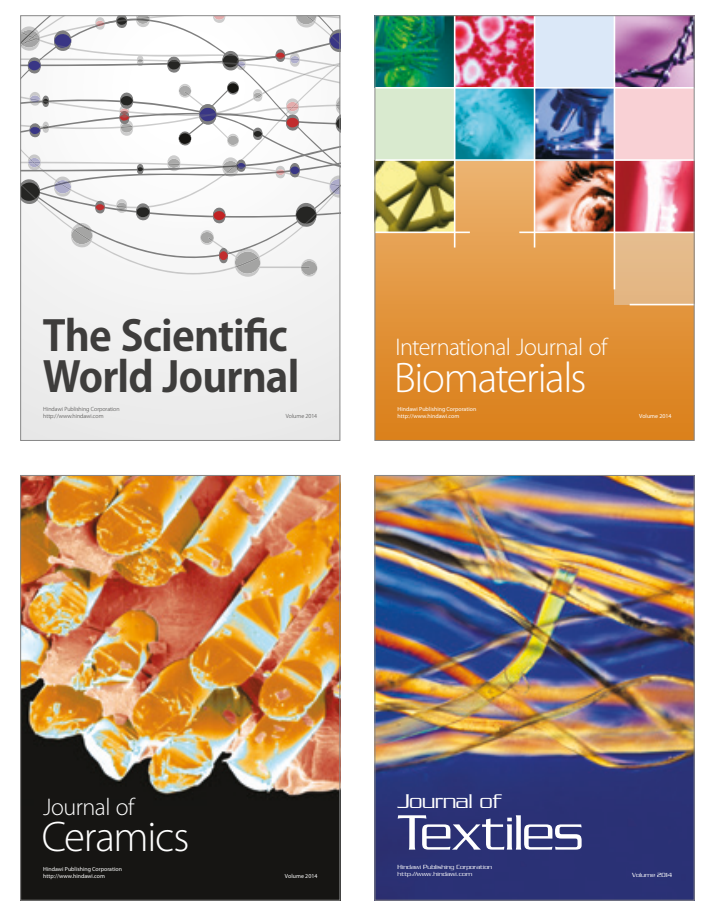